\title{
Educational Belief and Management Dilemma of Middle Managers in Local Normal Universities
}

\author{
Li Xuejiao ${ }^{1,2,}$ ahang Yaqi ${ }^{1, b}$ \\ ${ }^{1}$ College of Education, Northwest Normal University, Lanzhou,Gansu, China \\ College of Teacher Education, Yuxi Normal Universety, Yuxi, Yunnan, China \\ lixuejiao@yxnu.edu.cn \\ b2018103027@nwnu.edu.cn
}

\begin{abstract}
Belief can guide, maintain and predict the occurrence and development of behavior. Educational belief not only has an impact on Teachers' education and teaching, but also can regulate the work of normal university administrators. After interviewing two vice presidents of secondary colleges in local normal universities, it is found that the role of educational belief in leading managers' work is very limited. Because of the deviation of identity and less management autonomy, middle managers are facing great challenges in the actual management work. It is necessary to think about the management of secondary colleges in Local Normal Universities from a more macro and systematic perspective, which provides a new research direction for researchers.
\end{abstract}

Keywords: Educational Belief, Local Normal University, Middle Managers, Management Dilemma

\section{地方师范院校中层管理者的教育信念与管理困境}

\author{
李雪皎 $1,2, \mathrm{a}$ 张雅琪 $1, \mathrm{~b}$
}

1 西北师范大学教育学院, 兰州, 甘肃, 中国

玉溪师范学院教师教育学院, 玉溪, 云南, 中国

alixuejiao@yxnu.edu.cn

b2018103027@nwnu.edu.cn

\section{摘要}

信念能够对行为的发生和发展起指导、维持和预测作用。教育信念不但对教师的教育教学有影响, 对于师范院 校管理者的工作也能够起调节作用。通过对地方师范院校两位二级学院的副院长进行访谈后发现, 教育信念引 领管理者工作的作用十分有限。因为身份认同偏差、管理自主权较少等原因，中层管理者们在实际的管理工作 中面临着很大的挑战。有必要从更为宏观、系统的角度来思考地方师范院校二级学院的管理问题, 这给研究者 提供了新的研究方向。

\section{关键词: 教育信念 地方师范院校 中层管理者 管理困境}

\section{1. 问题提出}

信念可理解为个体对于有关自然和社会的某种 理论观点、思想见解坚信不移的看法 ${ }^{[1]}$ 。信念对个体 的行为有重要影响, 能够对行为的发生和发展起指导、 维持和预测作用。教育信念是指教师或教育领域的相 关人员 (管理者、师范生等) 对于教育的稳定的认识、 理解和假设。对于教师而言, 教育信念是他们在教学 情境中进行教学活动的内心向导; 对于学校管理者来
说，教育信念是其在协调和监管工作的过程中，努力 使教育目标能够得以实现的指路明灯。教育最直接的 体现是在课堂上，在师生关系中，但其背后的课程、 培养方案等教育载体都离不开学校管理机构的支持。 教育信念在师范院校的实际管理中究竟扮演了怎样 的角色？教育信念的不同在多大程度上会导致管理 者的管理差异? 这是一个值得探究的问题。 


\section{2. 研究背景}

党的十八大之后，党中央、国务院相继出台《乡 村教师支持计划（2015-2020 年)》和《中共中央国 务院关于全面深化新时代教师队伍建设改革的意见》, 高度重视教师队伍建设的顶层设计和系统推进。高师 院校作为教师培养的主力阵地在新时代应该发挥重 要作用, 而作为为中国农村培养教师的地方师范院校 则更应加强管理、努力提升,培养优秀教师。

高校的管理涉及多个层次的系统运作，其中二级 学院是界于校级与系级管理阶层之间的大学次级组 织形式, 管理内容包括开展教学、科研、人才培养和 行政事务等方面。二级学院是校级层面的教育思想是 否能够得到贯彻, 一线教师和学生的发展需求能否得 到满足的关键。从理论上讲, 管理者的教育信念势必 会在实践中对教育管理起促进或阻碍的作用。然而目 前这个领域还鲜有人研究, 故笔者对教育信念与地方 师范院校中层管理的关系进行了探索。

\section{3.研究方法}

\section{1 研究对象}

为更好地突出“师范院校”的特点, 本研究选取了 云南某省属全日制普通本科院校 (简称 $Y$ 校) 的教师 教育学院管理者作为研究对象。

$\mathrm{Y}$ 校的教师教育学院成立于 2001 年, 前身是教 育系。2006 年, 教育系与基础教育系合并成立了教育 学院; 2016 年, 学校以教育学院为基础, 组建成立了 教师教育学院。教师教育学院设有小学教育、学前教 育、教育技术学 3 个本科专业, 同时承担着全校师范 专业的教师教育通识必修课教学任务。

接受访谈的两名副院长皆为女性, 职称都是副教 授，具体信息见下表。

表 1 受访者基本信息

\begin{tabular}{|c|c|c|c|c|}
\hline $\begin{array}{l}\text { 受 } \\
\text { 访 } \\
\text { 者 }\end{array}$ & $\begin{array}{l}\text { 年 } \\
\text { 龄 }\end{array}$ & $\begin{array}{l}\text { 担任副院 } \\
\text { 长的时间 }\end{array}$ & $\begin{array}{l}\text { 履职 } \\
\text { 经历 }\end{array}$ & 求学经历及专业 \\
\hline A & 48 & 15 年 & $\begin{array}{c}\text { 教学秘书 } \rightarrow \text { 班主任 } \\
\rightarrow \text { 副院长 }\end{array}$ & $\begin{array}{c}\text { 本科: } 985 \text { 师范大学 (学 } \\
\text { 校教育) } \\
\text { 硕士: } 985 \text { 师范大学 (高 } \\
\text { 等教育) }\end{array}$ \\
\hline B & 42 & 1 个月 & $\begin{array}{c}\text { 班主任 } \rightarrow \text { 教研室主 } \\
\text { 任 } \rightarrow \text { 系主任 } \rightarrow \text { 副院 } \\
\text { 长 }\end{array}$ & $\begin{array}{c}\text { 本科: 省属重点师范大学 } \\
\text { (教育学) } \\
\text { 硕士: 省属重点师范大学 } \\
\text { (发展与教育心理学) }\end{array}$ \\
\hline
\end{tabular}

\section{2 研究过程}

研究主要以开放式访谈的方式进行。两位副院长
分别接受了大约一个半小时的正式访谈。在征求了被 访者的同意后进行了录音。此外, 在资料分析过程中, 笔者又通过社交软件向两位被访者求证了部分问题, 力求其真实想法能够得到客观地呈现。

\section{4.研究结果与讨论}

我国学者对“教师教育信念”的认识并未统一, “大教育信念观”认为教育信念是对某种教育观念、教 育思想、教育理论的确认和坚信; 而 “小教育信念观” 指的是“教师教育信念”, 即教师在教学情境与教学历 程中, 对教学工作、教师角色、课程、学生、学习等 相关因素所持有且信以为真的观点 ${ }^{[2]}$ 。本研究综合了 两种观点, 提取了部分教育信念的子结构进行分析:

\section{1 受访者不认同自己的“管理者”角色}

两位副院长在履职时间上有很大差异, 但在角色 认同上却很一致。A 老师自 2004 年起一直担任副院 长一职, 分管教学和科研。B 老师则是 2004 年研究 生毕业后进入 Y 校教师教育学院工作, 一个多月前被 提拔为副院长。但在提及学院管理问题的时候, 她们 都表达了对于自己“管理者”身份的不认同。

$\mathrm{A}$ 老师：我一直觉得我好像不是个管理者，只 是个做事情的执行者。

B 老师：我只是个干活的人，并没有真正承担 组织管理，更没有决策的这种功能在里面，都是上 面决定好了什么，然后就开始照着人家的这个决策 去把这些事情给落实了 ......学院的教学质量啊，办 学水平啊，老师的专业发展啊，学生的素质提升啊 可能这些才是所谓管理问题要解决的。但是好像我 就是在到处“灭火”，一件事情接着一件事情，而且 大量的事情似乎都是明知不可为而为之。

导致管理者把自己定义为“做事情的人”的原因 当然是多方面的, 但从受访者的言语中首先能感受到 的是作为所谓“管理者”的无力二二级学院要同时 配合教务处、学生处、科研处等多个职能部门的工作, 中层管理人员仅是“上传下达”就已经“疲于奔命”上级通知一来, 马上就要协调人员, 调动资源, 尽快 完成, 以便腾出手来准备接受下一项工作。并且很多 时候任务是叠加的, 这让管理者几乎无㗇深入地思考 学院管理和长远发展的问题。

其次, 中层管理者的自主决策权十分有限。基本 上级部门都“安排好了”, 二级学院只需要执行上级的 决定就行。正如两位受访者都提到的“(对上级部门) 完全没有道理可以讲”。在一个良性运行的系统中, 信 息和想法应该是能够上下流动的, 但 $\mathrm{Y}$ 校似乎只关注 了上层意志的执行, 而忽视了中层和下层的反馈。这 样一来，中层管理者把自己定义为“做事的人”也就不 
足为奇了。

社会身份认同理论认为, 如果社会身份令人不满, 人们会努力离开现属群体并加入更有利的群体。然而 受访的两位副院长都没有离开现属群体, 但值得注意 的是，虽然两位副院长都不认同自己的“管理者”角色， 却都十分认同自己“教师教育者”的角色。这不禁令人 唏嘘：如果能够将“教师教育者”和“管理者”的角色融 合起来，势必对于该学院的发展会有更大的促进，那 我们是否需要考虑, 如何在既定的制度下最大限度地 实现二级学院管理者的管理自主呢?

\section{2 受访者都主张“教育要以学生为本”}

两位副院长都认同“教育应该以学生为本”的教 育理念, 认为要“把学生的利益放在心上”。不过在培 养学生方面, 二人的侧重点却有所不同。 $\mathrm{A}$ 老师认为 培养学生对教育的信念和情怀最重要, 而 $\mathrm{B}$ 老师则更 看重师范生的基本能力。

A 老师：我总觉得热爱是最重要的，因为只要 热爱 ( 教育)，学生就会自己去想办法学习（怎么 当一名好老师)。我们不可能什么都教会他们。

$\mathrm{B}$ 老师：(培养要) 以学生的能力发展为本， 以这个专业的最低要求为本.......径应该宽一些， 基础要广一点，我们(的师范生将来) 要处理基础 教育阶段的问题，理论要偏实用一点，更多的要打 牢基础。

产生分歧的原因大概与两位受访者的个性特质 和求学经历有关。A 老师偏感性些, 喜欢“仰望天空”, 在访谈过程中多次提及本科阶段老师们对她的影响, 坚定了教育的信念和情怀。B 老师偏理性些, 更愿意 “俯视大地”, 当提到母校对自己的影响时, 她认为更 多的是老师们作为个体的自身魅力, 而非“教师教育 者”的魅力。此外, B 老师是从师范学校保送上的本科, 而中师阶段的教育很重视对师范生教学技能的培养, 这或许也对 B 老师的观念造成了影响。

从“热爱”和“能力”两个培养目标的比较来看, 前 者作为上位的培养目标, 确实能够激发学生的自主性, 推动行为的发生。但在操作层面, “能力”的培养更容 易达成, 对教师的自身素养要求也略低——毕竟想要 培养师范生热爱教育事业, 教师首先就要对“教师教 育者”的身份深度认同, 并把对教育的信念付诸于实 践, 而就 Y 校教师教育学院的现有师资而言还远达不 到这个水平。

有意思的是, 当谈及人才培养方案的课程设置时, 针对 $\mathrm{Y}$ 校大部分专业的总学分都高于教育部规定的 学分上限的现状, 两位老师都表达了“没必要......应 该加大选修课的力度”的观点。可见虽然对培养重点 的想法有所不同, 但“以学生为本”的教育信念让她们
在课程设置的时候又站到了同一阵营。

\section{3 受访者都对本学院的发展寄予希望}

当笔者追问: “如果有条件，你作为副院长，最想 为学院做什么? ”时, 两位老师也产生了较大差异。

A 老师：我最想把青年教师的队伍带起来...... 最起码要 (让他们) 保持 (对教育) 的激情.......我 觉得热爱太重要了......我总认为如果能有这么一个 群体的老师，那这个群体给学生本身的示范就很 好......我总觉得大学只是要给学生奠定一个基础。 就像母校给我的，就是对教育的相信和热爱。

B 老师：因为我现在还处在一个学习的阶段， 所以想的还不是太多......我还是觉得教学应该是一 个学院运转的基本的核心。不管是办专业办学院， 还是说大一点办教育，你能够提供的可能也就是“课 程”这种产品，这可能是一个底线，所以还是想把它 管好，但现实很难......现在我们 (学院) 不是“人不 够”的问题，是“人不对”的问题（指教师专业不对口， 教师矛盾影响教学 )...... ( 希望) 我能更好的去解 决老师之间的矛盾，或者让这些矛盾冲突不那么尖 锐。

抛开“分管领域不同”这个因素以外，两位老师的 个性特点在这个问题的回答上再次得以体现。其实回 答的差异并不重要, 重要的是她们虽然要面对工作中 许许多多的“不可为”、“没道理”，但依然对学院有深 厚的情感, 对学院的发展有殷切的期待, 并且也愿意 奉献自己的力量。可以预见, 教育信念会给她们的教 育工作和管理工作护航。

\section{5.结论}

此次访谈最初只是想探究教育信念能否在师范 院校管理者的工作中起指导作用, 未曾想却发现了地 方师范院校中层管理者的工作困境和身份困扰。本研 究的局限在于只访谈了二级学院的副院长, 没能访谈 到院长。而相对于副院长来说, 院长的自主管理权要 大些。那么院长的管理困境是否会少一点, 是否能够 更认同自己“管理者”的角色呢? 我们不得而知。

此外, 在访谈过程中发现, 两位副院长都表达了 想要“有一个更加合适的人来任院长”的愿望。这会不 会意味着, 现任院长本人可能也是两位副院长肩上的 枷锁呢? 就二级学院管理而言, 有学者认为应实行院 长负责制[3]，那院长的选拔又该以什么为标准呢?

本研究目前无法去探讨这些更为宏大和深入的 问题。回归到研究的起点, 我们发现引领两位副院长 
在困境中艰难前行的, 正是她们作为教育者的初心, 是对于教育坚定的信念。而这份信念正是教师和学校 管理者为教师职业赋予的意义和动力来源 ${ }^{[4]}$, 或许也 召唤着基于差异教育信念的学校管理新体系 ${ }^{[5]}$ 的到来。

\section{REFERENCES}

[1] Guoliang Yu, Ziqiang Xin. Teacher's Belief and its Significance to Teacher Training. Educational Research, 2000(5): 16-20.

[2] Li Liu, Yanfang Yang. A review of the Research on Teachers' Educational Beliefs. Journal of Inner Mongolia Normal University(Educational Science Edition), 2008(12): 45-51.

[3]Rujun Cao. Tentative Discussing the Managing Mode of Professionally Secondary-grade School.Fudan Education Forum, 2003(4):55-57.

[4] Mingren Zhao. Pre-endowed Identity, Institutional Identity and Constructive Identity-Analysis of the Identity of Normal University Students. Educational Research, 2013(6): 78-85.

[5] Yanyong Che. School Management based on Different Educational Beliefs. Journal of the Chinese Society of Education,2020(9):103. 